\title{
Determination of Correlation between Stomatal Density and Gas Exchange Traits in Guava
}

\author{
Banoth Shiva*, A. Nagaraja, Manish Srivastava and A.K. Goswami \\ Division of Fruits and Horticultural Technology, ICAR-Indian Agricultural Research Institute, \\ New Delhi-110 012, India \\ *Corresponding author
}

\section{A B S T R A C T}

The control of gaseous exchange between the leaf and bulk atmosphere by stomata governs $\mathrm{CO}_{2}$ uptake for photosynthesis and transpiration, determining plant productivity

\section{Keywords}

Guava, Correlation analysis, Stomatal number and gas exchange apparatus.

Article Info

Accepted:

17 July 2017

Available Online:

10 September 2017 and water use efficiency. The balance between these two processes depends on stomatal responses to environmental and internal cues and the synchrony of stomatal behavior relative to mesophyll demands for $\mathrm{CO}_{2}$. Stomatal conductance (Gs) is an important trait responsible for the genotypic difference in gas diffusion for photosynthesis and transpiration in guava (Psidium guajava L.). Correlation studies among different horticultural traits indicated that leaf stomatal density was positively correlated with stomatal conductance (Gs), to net photosynthesis rate (Pn, 0.110), and leaf net $\mathrm{CO}_{2}$ assimilation rate (An, 0.177) (Table 1).Similarly, number of stomata is negatively correlated with Transpiration (E, 0.193). Further our results indicated that there is highly significant positive correlation among net photosynthesis rate, transpiration rate, stomatal conductance and internal $\mathrm{CO}_{2}$ concentration $(\mathrm{Ci})$. The differences in leaf stomatal numbers and gas exchange values that existed among the genotypes can be taken into consideration as selection criteria for guava to be grown in regions with varying environmental conditions. These findings also add new insights into the correlations among traits involving carbon and water economy in guava.

\section{Introduction}

In order for plants to function efficiently, they must balance gaseous exchange between inside and outside the leaf to maximize $\mathrm{CO}_{2}$ uptake for photosynthetic carbon assimilation (A) and to minimize water loss through transpiration (Nilson and Assmann, 2007). Stomata are the "gatekeepers" responsible for all gaseous diffusion, and they adjust to both internal and external environmental stimuli governing $\mathrm{CO}_{2}$ uptake and water loss. The pathway for $\mathrm{CO}_{2}$ uptake from the bulk atmosphere to the site of fixation is determined by a series of diffusional resistances, which start with the layer of air immediately surrounding the leaf (the boundary layer). Stomatal conductance for gas diffusion (gs) and transpiration is closely correlated with leaf photosynthesis in plants (Kuroda and Kumura, 1990; Miah et al., 1997; Kanemura et al., 2005). Strong indications have been obtained for a major influence of gs on crop growth rate during reproductive period and yield of some crop species in previous studies (Lu et al., 1994; 
Fischer et al., 1998; Horie et al., 2006). Therefore, it is expected that crops would be improved by manipulating the morphological characteristics of stomata (Jones, 1992; Ishimaru et al., 2001), but the effect of the improvement on crop growth rate or yield is not evident. Many researchers have reported stomatal density responses to various environmental factors, such as elevated $\mathrm{CO}_{2}$ concentration (Woodward, 1987), heat stress (Beerling and Chaloner, 1993), salt stress (Zhao et al., 2006), drought (Galme's et al., 2007), precipitation change (Yang et al., 2007), and plant density (Zhang et al., 2003). Sahin and Soylu (1991) showed the effect of drought on the stomata frequency of selected chestnut types. In annual plants stomatal conductance was found to be related to yield in some instances. Ulloa et al., (2000) confirmed that high stomatal conductance was associated with high cotton lint yields at supra-optimal temperatures for the cotton crop under irrigated environments.

The purposes of this study were to determine the response patterns of stomatal density to different gas exchange characteristics, and to develop the relationship of stomatal density with gas exchange. An understanding of the relationship between stomatal features and environmental factors would be of considerable importance for the better fruit tree growth on the warming globe.

\section{Materials and Methods}

\section{Plant materials}

The present investigation was carried out during the month of May 2013 on 22 indigenous guava cultivars of 6 years age maintained by the Division of Fruits and Horticultural Technology, Indian Agricultural Research Institute (IARI), New Delhi, India located at the altitude of $228 \mathrm{~m}$ above mean sea level with $28040^{\prime} \mathrm{N}$ latitude and 770 13'
E longitudes. The average maximum temperature in summer is about $\sim 32.8^{\circ} \mathrm{C}$ and minimum temperature about $\sim 21.7{ }^{\circ} \mathrm{C}$ and the average annual relative humidity of this area is about $64 \%$ with rainfall of about $680 \mathrm{~mm}$. The trees were maintained under uniform cultural practices. The experiment was laid out in Randomized Block Design (RBD) with three replications as per the procedure outlined by Panse and Sukhatme (1955).

\section{Gas exchanges}

Gas exchange measurements were made once in a day (from 9.00 to 11.00 AM) on south facing mature leaves by using a portable infrared gas analyzer system (IRGA) (Li-Cor 6200, Li-Cor Biosciences, Lincoln, NE, USA)with an $11 \mathrm{~cm}^{2}$ window leaf chamber at $\mathrm{CO}_{2}$ concentration of $360 \mathrm{~cm} 3 / \mathrm{m} 3$ and $21 \%$ $\mathrm{O}_{2}$ or $2 \% \mathrm{O}_{2}$ air conditions (to inhibit the apparent photosynthesis) for net photosynthesis rate, transpiration rate, stomatal conductance and internal $\mathrm{CO}_{2}$ concentration $(\mathrm{Ci})$. The gas exchange rates were determined at each step after maintaining the leaf for 5-10 $\mathrm{min}$ at the new $\mathrm{CO}_{2}$ concentration. All measurements were done in fully expanded leaves (usually the sixth to eighth from the top) of four different plants just before midday to reduce diurnal variation interference (Cartechini and Pallioti, 1995). The data was stored in the data logger in the equipment and analyzed statistically.

\section{Stomatal determinations}

The impression approach was used to determine leaf stomatal density, which was expressed as the number of stomata per unit leaf area (Radoglou and Jarvis, 1990). The leaves selected were those for which gas exchange was measured. The abaxial epidermis of the leaf was cleaned first using a degreased cotton ball, and then carefully smeared with nail varnish in the mid-area 
between the central vein and the leaf edge, for approximately $20 \mathrm{~min}$. The thin film (approximately $5 \mathrm{~mm} 315 \mathrm{~mm}$ ) was peeled off from the leaf surface, mounted on a glass slide, immediately covered with a cover slip, and then lightly pressured with fine point tweezers. Numbers of stomata (s) for each film strip were counted under a photomicroscope system with a computer attachment (Olympus, CX40RF200). Impressions were taken from the six youngest, fully expanded leaves for each plant and stomata number was calculated per $\mathrm{mm}^{2}$.

\section{Statistical analysis}

Observations on physiological traits were subjected to analysis using standard statistical package and mean the difference between treatments will be separated using Randomized Block Design (RBD) with the experimental unit consisted of a six leaf sample taken from one selected plant. Four plants per treatment were employed as replications. All these leaves were at the same physiological age of those used for the gas exchange measurements. The data on different parameters were analyzed by using analysis of variance (ANOVA) by using Statistical Package for Agricultural Workers (STAT OP Sheoran http://14.139.232.166/ opstat/default.asp). Valid conclusions were drawn only on significant differences between the treatment mean at 0.05 level of probability.

\section{Results and Discussion}

The correlation studies among different traits of guava genotypes would certainly provide an idea, which might be utilized for selection of desirable parameters for future breeding programs in guava. The highly significant positive correlation between desirable characters is favorable to a plant breeder because it might help in simultaneous improvement of both the characters. On the other hand, the negative correlation would hinder the synchronized expression of both the characters. In such a situation, it would require to making some compromise including economic ones. Photosynthetic capacity of crop plants has been widely used as most important physiological attribute to evaluate plant vigor, biomass and ultimately economic yield.

The correlation between E, Gs, Pn were analyzed and showed in table 1. Among the genotypes, differences in the functioning of the photosynthetic apparatus were found. Leaf stomatal density was positively correlated with stomatal conductance (Gs) to net photosynthesis rate $(\mathrm{Pn}, 0.110)$, and leaf net CO2 assimilation rate (An, 0.177) (Table 1). Transpiration is another important parameter, which is directly linked with temperature sensitivity vis a vis water availability for a plant. The number of stomata is negatively correlated with Transpiration (E, -0.193). However, the relationship between stomatal index and gas exchange parameters was remarkably scattered with no significant association found (data not shown). Further our results indicated that there is highly significant positive correlation among net photosynthesis rate, transpiration rate, stomatal conductance and internal $\mathrm{CO}_{2}$ concentration $(\mathrm{Ci})$.

Photosynthetic capacity is closely linked to $\mathrm{SD}$ (Xu and Zhou, 2008). Leaf A was negatively correlated with SD when plants were exposed to elevated $\mathrm{CO}_{2}$ (Woodward, 1987; Ainsworth and Rogers, 2007), whereas a positive correlation occurred when grass was subjected to a water status gradient $(\mathrm{Xu}$ and Zhou, 2008). Moreover, photosynthetic potential might be enhanced with increased SD in Arabidopsis by a modulating gas diff usion function, as was recently reported by Tanaka et al., (2013). 
Table.1 Correlation among stomatal number and gas exchange characteristics

\begin{tabular}{|c|l|c|c|c|c|c|}
\hline S. No. & Parameter & $\begin{array}{c}\text { Stomatal } \\
\text { Density }\end{array}$ & $\begin{array}{c}\text { Intercellular } \\
\mathrm{CO}_{2}(\mathrm{An})\end{array}$ & $\begin{array}{c}\text { Transpiration } \\
(\mathrm{E})\end{array}$ & $\begin{array}{c}\text { Stomatal } \\
\text { conductance }(\mathrm{Gs})\end{array}$ & $\begin{array}{c}\text { Net Photosynthesis } \\
(\mathrm{Pn})\end{array}$ \\
\hline 1 & Stomatal Density & 1.000 & 0.177 & -0.193 & 0.198 & 0.110 \\
\hline 2 & Intercellular $\mathrm{CO}_{2}$ & & 1.000 & $0.984^{*}$ & $0.943^{*}$ & $0.466^{*}$ \\
\hline 3 & Transpiration & & & 1.000 & $0.971^{*}$ & $0.502^{*}$ \\
\hline 4 & Stomatal conductance & & & & 1.000 & $0.569^{*}$ \\
\hline 5 & Net Photosynthesis & & & & & 1.000 \\
\hline
\end{tabular}

Critical values for Pearson's correlation coefficient of two tailed test: *, significant at $5 \%$ level of significance (0.404).

In this case, the $\mathrm{A}$ increase at elevated $\mathrm{CO}_{2}$ is tightly associated with increased SD. When stomatal density increases independently of stomatal size, improvement of gs is expected (Schlüter et al., 2003), but there are a number of experimental reports showing that increased stomatal density does not enhance gs (Jones, 1977; Kawamitsu et al., 1996). This is because stomatal density negatively correlates with stomatal size. Our study showed that genotypic difference of stomatal density was not related to that of gs, but suggested two different ways to achieve highgs. One is to have high specific stomatal conductance, as observed in the varieties in Mridula showing high gs despite with low stomatal density (data not shown). The other is to have high stomatal density.

Many reports showed an increase in stomatal density and a decrease in cell size under water deficit, indicating that an adaptation to drought could occur (Martinez et al., 2007). The compromise between stomatal size and density is related to the limitation of the leaf area allocated to stomata. Thus, it was suggested (Franks et al., 2009) that taking into account the leaf area limitation, there is a point when the only way to increase stomatal conductance is by decreasing stomatal size and increasing density, since increasing stomatal conductance by increasing size will require a greater percentage of leaf surface allocated to stomata and a higher change in the leaf area. Several researchers
(Hetherington and Woodward, 2003; Russo et al., 2010) had reported that smaller stomata are better at improving WUE, due to their more rapid response to changes in environmental conditions such as humidity (Drake et al., 2013).In a recent study, it was revealed (Dow et al., 2014) that high stomatal density restricted $\mathrm{CO}_{2}$ diffusion and lowered photosynthesis. These findings were explained by the reduced functional capabilities of the guard cells from reduced availability of ions required for driving membrane processes, as well as the influence of turgor pressure for adjacent guard cells and the disruption of signalling processes due to the close proximity of the guard cells.

Some studies (Zhao et al., 2015) had also established significant negative correlations of stomatal density with photosynthesis and demonstrated that higher stomatal density reduced leaf photosynthesis. They argued that small stomata could maintain the pores opening with lower guard cell turgor pressures compared with larger stomata. The higher stomatal density and reduced stomatal size responding to drought can effectively inhibit transpirative water loss and better ensure water balance (Bosabalidis and Kofidis, 2002).

In apples the stomatal behaviour of the leaves appears to be correlated with photosynthetic rate (Lakso, 1994). Several factors are known to control stomatal conductance, such as light, 
soil water potential, internal $\mathrm{CO}_{2}$ concentration as well as sink strength in trees. But, genotypical differences in stomatal conductance were often neglected. The results of this study showed that stomatal conductance values of the guava genotypes grown in the same conditions greatly varied. Also, a low stomatal sensitivity to drought in benefit of an increase in growth would probably be a more successful strategy under the competitive conditions during tree establishment (De Lucia et al., 1991). The stomatal conductance seems to be independent of stomatal frequency or stomata size, since there was no significant relation between them in all genotypes tested (data not shown).In cotton, high stomatal conductance might confer some adaptive advantage to genotypes that experience supra-optimum temperatures (Ulloa et al., 2000). However, unlike cotton, fruit trees are penrennial plants with more complex physiological features that are difficult to be related. Using shading nets in apricots resulted in higher leaf stomatal conductance values than in exposed plants (Nicolas et al., 2005). Thus, climatological differences should be taken into consideration when stomatal conductance values are to be discussed. The result of this study provided evidence that there are cultivar differences with respect to stomatal frequency and stomatal conductance. Therefore, this information is important in the development of adaptation studies, particularly concerning heat stress to which trees experience in summer. Improving regulation capacity in stomatal traits by breeding selection and/or genetic methods would enable plants to acclimate to environmental stresses, such as drought. While genetic variation in intrinsic TE for any given level of conductance may be only one of a number of sources of variation in crop TE in the field, this study indicates that it could provide a useful target for breeding programmes if reliable and costeffective screening can be implemented.

\section{Acknowledgement}

I express my sincere thanks to the Head, Division of Fruits and Horticultural Technology, ICAR- IARI, New Delhi, for providing me support and technical guidance in all course of my field and lab work.

\section{References}

Beerling, D.J., and Chaloner, W.G. 1993. The impact of atmospheric $\mathrm{CO}_{2}$ and temperature change on stomatal density: observations from Quercusrobur Lammad leaves. Annals of Boty, 71: 231-235.

Bosabalidis, A. M., and Kofidis, G. 2002. Comparative effects of drought stress on leaf anatomy of two olive cultivars. Plant Sci., 163: 375-379.

Cartechini, A., and Pallioti, A. 1995.Effect of shading on vine morphology and productivity and leaf gas exchange characteristics in grapevines in the field. Amer. J. Enology and Viticlr, 46:227-34.

De Lucia, E.H., and Schlesinger, W.H. 1991. Resource-use efficiency and drought tolerance in adjacent Great Basin and Sierran plants. Ecol., 72: 51-58.

Dow, G. J., Bergmann, D. C. and Berry, J. A. 2014.An integrated model of stomatal development and leaf physiology. New Phytologist, 201 (4): 1218-1226.

Drake, P. L., Froend, R. H. and Franks, P. J.2013. Maller, faster stomata: scaling of stomatal size, rate of response, and stomatal conductance. J. Exp. Bot., 64: 495-505.

Fischer, R.A., Rees, D., Sayre, K.D., Lu, Z.M., Condon, A.G. and Saavedra, A.L. 1998. Wheat yield progress associated with higher stomatal conductance and photosynthetic rate, and cooler canopies. Crop Sci., 38: 1467-1475.

Franks, P. J., Drake, P. L. and Beerling, D. J. 
2009. Plasticity in maximum stomatal conductance con strained by negative correlation between stomatal size and density: an analysis using Eucalyptus globules. Plant Cell Environ, 32: 1737 1748.

Galme's, J., Flexas, J., Save, R. and Medrano, H. 2007. Water relations and stomatal characteristics of Mediterranean plants with different growth forms and leaf habits: responses to water stress and recovery. Plant and Soil, 290: 139-155.

Hetherington, A. M., and Woodward, F. 2003. The role of stomata in sensing and driving environmental change.Nature, 424: 901-908.

Horie, T., Matsuura, S., Takai, T., Kuwasaki, K., Ohsumi, A. and Shiraiwa, T. 2006. Genotypic difference in canopy diffusive conductance by a new remotesensing method and its association with the difference in rice yield potential. Plant Cell Environ, 29: 653-660.

Ishimaru, K., Shirota, K., Higa, M. and Kawamitsu, Y. 2001.Identification of quantitative loci for adaxial and abaxial frequencies in Oryza sativa. Plant Physiol. Biochem., 39: 173-177.

Jones, H.G., 1977. Transpiration in barley lines with differing stomatal frequencies. J. Exp. Bot., 28: 162-168.

Jones, H.G., 1992. Plants and microclimate. Second edition. Cambridge university press, Cambridge.346-350.

Kanemura, T., Homma, K., Ohsumi, A., Narisu, Horie, T., Shiraiwa, T., Ebana, K., Uga, Y., Kojima, Y. and Fukuoka, S. 2005. Analysis of genetic variability in yield-related traits of rice using global core collection. II. Leaf photosynthetic rate and associated factors. Jpn. J. Crop Sci., 74 (ex.2): 238-239.

Kawamitsu, Y., Agata, W., Hiyane, S., Murayama, S., Nose, A. and Shinjo, Y. 1996. Relation between leaf gas exchange rate and stomata. I. Stomatal frequency and guard cell length in $\mathrm{C}_{3}$ and $\mathrm{C}_{4}$ grass species. Jpn. J. Crop Sci., 65: 626-633.

Kuroda, E., and Kumura, A. 1990.Difference in single leaf photosynthesis between old and new rice varieties. I. Single-leaf photosynthesis and its dependence on stomatal conductance. Jpn. J. Crop Sci., 59: 283-292.

Lakso, A.N., 1994. Apple. In: Schaffer B, Andersen PC (Eds.), Handbook of Environmental Physiology of Fruit Crops, Temperate Crops, vol.1. CRC Press, Boca Raton, FL.

Lu, Z., Radin, J.W., Turcotte, E.L., Percy, R. and Zeiger, E. 1994. High yields in advanced lines of pima cotton are associated with higher stomatal conductance, reduced leaf area and lower leaf temperature. Physiol. Plant., 92: 266-272.

Martinez, J. P., Silva, H., Ledent, J. F. andPinto,M. 2007. Effect of drought stress on the osmotic adjustment, cell wall elasticity and cell volume of six cultivars of common beans (Phaseolus vulgaris L.).Eur. J.Agrny., 26: 30-38.

Miah, M.N.H., Yoshida, T. and Yamamoto, Y. 1997.Effects of nitrogen application during ripening period on photosynthesis and dry matter production and its impact on yield and yield components of semidwarf indica rice varieties under water culture conditions. Soil Sci. Plant Nutr, 43: 205-217.

Nicolas, E., Torrecillas, A., Amico, J.D. and Alarcon, J.J. 2005. Sap flow, gas exchange and hydraulic conductance of young apricot trees growing under shading net and different water supplies. J. Plant Physiol., 162: 439-447.

Radoglou, K.M., and Jarvis, P.G. 1990. Effects of $\mathrm{CO}_{2}$ enrichment on four poplar clones. II. Leaf surface 
properties. Annals of Botny, 65: 627632.

Russo, S. E., Cannon, W. L. Elowsky, C., Tan, S. and Davies, S. J. 2010.Variation in leaf stomatal traits of 28 tree species in relation to gas exchange along an edaphic gradient in a Bornean Rain Forest. Amer. J. Bot., 97: 1109-1120.

Sahin, T., and Soylu, A. 1991. A study on leaf and stomatal properties of some selected chestnuts. Uludag University No: 10: 20.

Schlüter, U., Mushak, M., Berger, D. and Altmann, T. 2003.Photosynthetic performance of an Arabidopsis mutant with elevated stomatal density (sdd1-1) under different light regimes.J. Exp. Bot., 54: 867-874.

Tanaka, Y., Sugano, S. S., Shimada, T. and Hara-Nishimura, I. 2013. Enhancement of leaf photosynthetic capacity through increased stomatal density in Arabidopsis. New Phytol, 198: 757764.

Ulloa, M., Cantrell, R.G., Percy, R.G., Zeiger, E. and Lu, Z. 2000. QTL analysis of stomatal conductance and relationship to Lint yield in an interspecific Cotton. J. Cotton Sci., 4: 10-18.

Woodward, F.I., 1987. Stomatal numbers are sensitive to increases in $\mathrm{CO}_{2}$ from preindustrial levels. Nature, 327: 617-618.

$\mathrm{Xu}, \quad$ Z.Z., and Zhou, G.S 2008.Responsesofleafstomataldensityto waterstatus and its relationship with photosynthesis in a grass. J. Exp. Bot., 59: 3317-3325.

Yang, L., Han, M., Zhou, G. and Li, J. 2007.The changes of water-use efficiency and stoma density of Leymus chinensis along Northeast China Transect. Acta Ecol. Sinica., 27: 16-24.

Zhang, X.Y., Wang, H.M., Hou, Z.D. and Wang, G.X. 2003.Stomatal density and distributions of spring wheat leaves under differentplanting densities and soil moisture levels. Acta Phytoecologica Sinica, 27: 133-136.

Zhao, S., Chen, W., Ma, D. and Zhao, F. 2006. Influence of different salt level on stomatal character in rice leaves. Reclaiming and Rice Cultivation, 6: 2629.

Zhao, W., Sun, Y., Kjelgren, R. and Liu, X. 2015.Response of Stomatal Density and Bound Gas Exchange in Leaves of Maize to Soil Water Deficit. Plants, Soils, and Climate Faculty Publications. Pp. 732.

\section{How to cite this article:}

Banoth Shiva, A. Nagaraja, Manish Srivastava and Goswami, A.K. 2017. Determination of Correlation between Stomatal Density and Gas Exchange Traits in Guava. Int.J.Curr.Microbiol.App.Sci. 6(9): 1328-1334. doi: https://doi.org/10.20546/ijcmas.2017.609.160 